\title{
УДК 811.512
}

\section{ПОСЛЕЛОГИ КАК СРЕДСТВА СВЯЗИ МЕЖДУ ЧАСТЯМИ СЛОЖНО-СПАЯННЫХ ПРЕДЛОЖЕНИЙ В КУМЫКСКОМ ЯЗЫКЕ}

Саидов Абдулкерим Магомедович к. П. Н., С. Н. с.

Рашидов Агаверди Алиевич к. ф. н., с. н. с. Институт языка, литературы и искусства ДФИЦ РАН, г. Махачкала

Аннотация: В статье рассматриваются вопросы сущности сложноподчиненных предложений синтетического типа в кумыкском языке в некотором сравнении с русским языком. Подробно анализированы структура и семантика сложно-спаянных предложений, спаянные части которых подчиненны главной при помощи послелогов.

Ключевые слова: синтаксис, сложноподчиненное предложение, сложноспаянное предложение, форма сказуемого, спаятельные средства связи, послелог.

\section{POSTPOSITIONS AS A MEANS OF COMMUNICATION BETWEEN PARTS COMPLEX SOLDERED SENTENCES IN THE KUMYK LANGUAGE}

\section{Saidov Abdulkerim Magomedovich Rashidov Agaverdi Alievich}

\footnotetext{
Abstract: The article deals with the essence of complex sentences of synthetic type in the Kumyk language in some comparison with the Russian language. The structure and semantics of complex soldered sentences are analyzed in detail, the soldered parts of which are subordinated to the main one using postpositions.

Key words: syntax, compound sentence, compound sentence, predicate form, conjugate means of communication, postposition.
} 
В кумыкском языке сложно-спаянные предложения как таковые не исследованы, если не иметь в виду нескольких статей автора, где обозначена эта проблема $[6,7]$. В кумыкском языке они до сих пор рассматриваются в составе сложноподчиненных предложений (по подобию русского сложноподчиненного предложения).

В 1982 году «исследователь В.Г. Адмони предложил назвать такие придаточные предложения спаянными без слова «придаточное», которое было принято некоторыми тюркологами: «Наличие сложно-спаянных предложений является специфической особенностью тюркских языков» [3, с. 395], однако в тюркологии наблюдаются расхождения как в характеристиках таких предложений, так и в их названиях.

А.Н. Кононов писал: «Причастие, как отглагольное прилагательное, синтаксически функционирует как определение, которое может иметь свое подлежащее, дополнение и другие второстепенные члены, передавая, таким образом, содержание придаточных определительных предложений. [4, 218]. Его точку зрения разделяет Н.К. Дмитриев: «Из среды причастных и деепричастных оборотов мы склонны выделить такие, в которых при причастии и деепричастии имеется свое грамматически выраженное подлежащее, отличное от остальной части фразы, мы склонны считать их тоже придаточными, хотя и переходного типа [2, с. 193].

К. Мусаев как бы полемизирует с Н.К. Дмитриевым: «Главным критерием для существования предложения является предикативность, а не наличие в предложении подлежащего, или сказуемого, или обоих вместе. К компоненту сложного предложения следует подходить также с этим требованием» [5, с. 289].

В близкородственном кумыкскому карачаево-балкарском языке У.Б. Алиев отмечает наличие двух типов придаточных предложений: «Придаточные предложения современных тюркских языков характеризуются в основном двумя противоположными типами, отличающимися друг от друга формами своих сказуемых. Сказуемые одного и наиболее распространенного типа придаточных предложений имеют форму, не свойственную сказуемым простого предложения, и потому почти не употребляются вне придаточных предложений. Этот тип сказуемых придаточных предложений выражается причастиями, деепричастиями, прилагательными, масдарами, словами отрицания и утверждения и т. д. в прямых формах и в формах косвенных падежей, с послелогами, аффиксами сравнения и др.» (1, с. 297). 
В этом вопросе имеются большие расхождения между кумыкским и русским языками: со сложноподчиненными предложениями русского языка сопоставимы только три вида кумыкского сложноподчиненного предложения: с придаточным причины, с придаточным условия и с придаточным места, сказуемые которых выражаются личными глаголами. Все остальные виды кумыкских придаточных предложений имеют другую структуру, отличную от структуры придаточных в русском языке. Сказуемые таких придаточных частей выражаются причастиями, деепричастиями, полупредикативными словами бар «есть», ёкъ «нет; не», которые не согласуются с подлежащими и потому не обладают полной предикацией, больше напоминая второстепенный член. Между частями подобных конструкций нет характерной для обычных сложноподчиненных предложений паузы, они не отделяются знаками препинания; на русский язык переводятся только как простое или как сложноподчиненное: Ол мен айтгъангъа къулакъ асмай букв. «Он не обращает внимания на сказанное мною; Он не обращает внимание на то, что я сказал». Данное предложение в кумыкском языке нельзя рассматривать ни как простое, ни как сложноподчиненное (хотя до сих пор подобные конструкции считаются сложноподчиненными предложениями). Главная часть данного предложения ол къулакъ асмай «он не обращает внимания» в отдельности является двусоставным предложением, сказуемое которого выражено фразеологическим оборотом къулакъ асмай букв. «ухо не варит» (/ не обращает внимания); зависимая часть мен айтгъангъа «на сказанное мною / на то, что я сказал» похожа на придаточную часть, которая может быть свободно заменена одним словом - причастием айтгъаныма «на сказанное (мною)» с аффиксом притяжательности 1-го лица -ымм, который замещает функцию субъекта (подлежащего), выраженного личным местоимением 1-го л., ед. ч. мен «я». Такие предложения, как было отмечено выше, по своим структурносемантическим особенностям, занимают промежуточное положение между простыми и сложными предложениями, что видно и из переводов на русский язык, которые представляют или простое, или сложное, или простое и сложное предложения. Мы считаем, что такие предложения нужно рассматривать отдельно, выделив их из системы сложноподчиненных предложений в самостоятельный подвид и принять название «сложно-спаянное предложение» (в кумыкском языке термин будет звучать как «бирикген къошма жумла»).

Рассмотрим сложно-спаянные предложения, в которых средствами связи спаянных частей с главными выступают послелоги, послеложные слова вместе 
с аффиксами падежей или без них. Все эти средства составляют словоформу сказуемых, основы которых выражаются причастиями, именами действий, словами бар «есть» или ёкъ «нет».

1. Послелоги булан «с; и», учун «для; за» многофункциональны: а) в простом предложении они входят в состав косвенного дополнения, выраженного в основном и винительном падежах: Атанг булан макътанма! «Не хвались своим отцом!»; Кёкден учар гёгюрчюн, ерге къонар ем учун (Фольк.) букв. «Из неба полетит голубь, на землю приземлится для корма» Сени булан мен де гелемен «С тобой и я иду»; б) послелог булан соединяет однородные подлежащие: Рашия булан Лайла - Абдулвагьап Сулеймановну эгизлери («Ёлдаш») «Рашид и Лейла - двойняшки Абдулвагаба Сулейманова»; в) в сложноспаянном предложении, выступая в составе сказуемого-причастия спаянной части, послелоги булан, учун приобретают другое значение: «что из того» и свободно могут заменять друг друга, т. е. эквивалентны: Мен айтгъан булан не пайда, овзю англамаса и Мен айтгъан учун не пайда, оьзю англамаса: «Что из того, что я сказал»; Ургъан булан савут овтмей гюбеден (Й. Къазакъ) «Что из того, что ударил: оружие, не пробивает щит».

Интересен тот факт, что спаянные части с такими словоформами сказуемых синонимичны словоформам сказуемых спаянных частей, подчиняющихся главной при помощи аффикса исходного падежа -дан, -ден. Ср.: Мен айтгъан уцун / булан не пайда, овзю англамаса и Мен айтгъандан не пайда, овзю англамаса? (перевод вверху). В обоих случаях действие подчиняющих членов происходит после завершения процесса, выраженного сказуемыми спаянных частей, которые выражают косвенный объект, являющийся причиной процесса, обозначенного подчиняющим членом. Разница между ними состоит в стилистическом употреблении: сказуемое с падежным аффиксом характерно в основном для письменной речи, с послелогом - для разговорной речи.

Спаянные части со сказуемым-причастием вместе с послелогами булан, учун иногда применяются и в уступительном значении: Авлетлери йыракъда тургъан булан, ата-анасы оланы гъайын этмей боламы!! (К. Абуков) «Если дети живут далеко, это не значит, что родители не заботятся о них».

2. В качестве средства связи между спаянной частью со сказуемымпричастием и главной частью выступает послелог саяльљ «из-за; из-за того, что; ввиду того, что». В таких случаях спаянная часть выражает причину совершения действия, обозначенного подчиняющим членом в главной части: 
$\overline{Я н г у р ~ я в г ъ а н ~ с а я л ь l, ~ а в л а к ъ ~ и ш л е р ~ т о к ъ т а л д ы ~(« Е ̈ л д а ш ») ~ « И з-з а ~ т о г о, ~ ч т о ~}$ пошел дождь, полевые работы приостановлены».

3. Если средством связи выступает послеложное слово къарамайльь «несмотря на то, что», то спаянная часть со сказуемым-именем действия выражает уступительное значение с противительным оттенком. В таких конструкциях сказуемое спаянной части обязательно осложняется прибавлением аффикса дательного падежа -гъa, -ге и усилительной частицы $\partial a$ / де. Схематически это выглядит так: подлежащее - сказуемое + гъ $a / z e+\partial a+$ къарамайль. Пример: Анасы шонча тилегенге де къарамайлы, Къурман гече сувгъа гетди (И. Къазиев) «Несмотря на убедительную просьбу матери, Курбан ночью ушел на речку» / Несмотря на то, что мать столько просила, Курбан ночью ушел на речку».

4. Сказуемое на -гъан / -ген + послелог сайын «по мере», подчиняясь главному, выражает время или степень совершения действия во времени: Гюн гётерилген сайын, гъава бек къыза эди (М. Хангишиев) «По мере, как солнце поднималось, воздух нагревался сильнее».

5. Сказуемое на -гъан / -ген + послелог гёре «по; так как; по тому, что; потому как» выражает причину действия, при этом словоформа сказуемого с послелогом гёре принимает аффикс направительного падежа -гъа / -ге: Тавда гючлю янгурлар явгъангъа гёре, оьзенлер ягъаларындан чыкъгъан (И. Керимов) «Реки вышли из берегов, так как в горах были сильные дожди»; «Башир тилегенге гёре, Марьям гьинкалгъа къазан толтуруп эт асды (М. Хангишиев) «По просьбе Башира Марьям сварила полную кастрюлю мяса для хинкала»

6. Сказуемое спаянной части на -гъан / -ген + аффикс местного падежа -да /-де, подчиняясь главной при помощи послелога йимик «как; будто, словно; наподобие», выражает сравнение действия или явления, обозначенного подчиняющим членом, с действием или явлением в спаянной части: Къошубуздан бираз арекде тюбек атылгъанда йимик тавуш болду (К. Абуков) «Чуть поодаль от нашего шалаша послышался звук, будто выстрелило ружье».

7. Спаянная часть со сказуемым на -гъан / -ген + послелог чакъbl выражает степень совершения действия, обозначенного подчиняющим членом: Сиз яхшы болгъан чакъв, сизге де яхшы болажакълар (К. Абуков) «Сколько вы будете добры, столько же и к вам будут относиться хорошо».

8. Спаянная часть со сказуемым на -гъан / -ген + аффикс исходного падежа -дан / -ден, подчиняясь главному при помощи послелога берли «с тех пор, как», выражает степень совершения процесса во времени, т. е. действие 
главной части начинается и продолжается со времени завершения действия спаянной части: Болат директор болгъандан берли, охутув-тарбиялав иш хыйль алгъa гетди (К. Абуков) «С тех пор, как Булат стал директором, учебновоспитательная работа значительно повысилась».

9. Спаянная часть со сказуемым на -гъан / -ген, подчиняясь главному при помощи послеложного слова сонг «после», показывает, что обозначенное подчиняющим членом действие начинается после окончания действия спаянной части: Дав битип къайтгъан сонг, Ибрагьим Керимов педагогика институтда охувун давам эте («Тангчолпан») «После окончания войны Ибрагим Керимов продолжил учебу в педагогическом институте».

10. Спаянная часть со сказуемым на -гъан /-ген, подчиняясь главному при помощи послеложного слова вакътиде «во то время, когда; когда» выражает время совершения действия, обозначенного подчиняющим членом в главной: Къурман гелген вакътиде уьйдегилер юхламагъа ятма онгарыльл тура эди (И. Къазиев) «Когда пришел Курбан, домашние собирались лечь спать».

Таким образом, послелоги и послеложные слова в кумыкском языке многофункциональны. Они образуют целую систему средств связи для соединения спаянной части сложно-спаянного предложения с главной в составе сказуемого, выраженного неличными формами глагола с падежными аффиксами или без них, выражая различные подчинительные отношения.

\section{Список литературы}

1. Алиев У.Б. Избранные труды: В 3 т. - Нальчик: Издательство М. и В. Котляровых, 2012. Т. 2: Синтаксис карачаево-балкарского языка. - 368 с.

2. Дмитриев Н.К. Грамматика кумыкского языка. М.-Л.: Наука, 1940. 203 c.

3. Закиев М.3. Татарская грамматика. Синтаксис. Казань: Татарское книжное издательство, 1995. - 576 с.

4. Кононов А.Н. Грамматика турецкого языка. М.-Л.: Наука, 1941. - 312 с.

5. Мусаев К.М. Синтаксис караимского языка. М.: Академия, 2003. - 347 c.

6. Саидов А.М. Средства связи частей сложноподчиненного предложения в кумыкском языке // Вестник ИЯЛИ, № 19, 2019. С. 31 - 34; Союзные слова как средства связи частей сложноподчиненного предложения в кумыкском языке // Ежемесячный международный научный журнал «Research-science», № 
4, 2019. Banská Bystrica, Словакия. С.19 - 22; К вопросу сложно-спаянных предложений в кумыкском языке // Вестник ИЯЛИ, № 20, 2019. С. 37 - 40.

7. Саидов А.М., Рашидов А.А. Особенности сложно-спаянных предложений в кумыкском языке // Современные научные исследования: актуальные вопросы, достижения и инновации: сборник статей IX Международной научно-практической конференции. В 2 ч. Ч. 2. - Пенза: МЦНС «Наука и Просвещение». - 2019. - 264 с. С. 65 - 68. 